DOI: $\underline{\text { https://doi.org/10.24127/ajpm.v10i3.3745 }}$

\title{
KECEMASAN MENGAJAR MATEMATIKA PADA PEMBELAJARAN ONLINE DAN DAMPAKNYA PADA METODE PENGAJARAN GURU
}

\author{
Endah Wulantina ${ }^{1 *}$, Fertilia Ikashaum ${ }^{2}$, Juitaning Mustika $^{3}$, \\ Nur Indah Rahmawati ${ }^{4}$, Angga Kurniawan ${ }^{5}$ \\ 1,2,3,4,5 Institut Agama Islam Negeri Metro, Lampung, Indonesia \\ * Corresponding author. Jl. Ki Hajar Dewantara, Iringmulyo, Kec. Metro Timur, Kota Metro, Lampung 34112 \\ E-mail: endahwulantina@metrouniv.ac.id ${ }^{1 *}$
}

Received 24 May 2021; Received in revised form 13 September 2021; Accepted 28 September 2021

\begin{abstract}
Abstrak
Tujuan penelitian ini adalah untuk mendeskripsikan tingkat kecemasan guru matematika di sekolah terhadap pembelajaran online; faktor-faktor kecemasan mengajar matematika pada pembelajaran online, dampak dari kecemasan mengajar matematika terhadap metode mengajar guru pada pembelajaran online. Metode penelitian yang digunakan adalah metode penelitian kualitatif deskriptif. Penelitian dilakukan pada 31 guru matematika yang mengajar pada pembelajaran online. Data dikumpulkan melalui kuesioner Mathematics Teaching Anxiety Scale (MTAS) sebanyak 19 item. Teknik analisis data yang digunakan terdiri dari tiga tahap yaitu reduksi data, display data dan verifikasi data. Hasil penelitian menunjukkan bahwa level kecemasan mengajar matematika guru pada pembelajaran online sebanyak 7 orang $(22,6 \%)$ kategori tingkat kecemasan tinggi, sebanyak 14 orang (58\%) kategori tingkat kecemasan sedang dan sebanyak 6 orang $(19,4 \%)$ kategori tingkat kecemasan rendah. Kecemasan mengajar matematika yang paling banyak dirasakan adalah terkait siswa yang tidak dapat berpartisipasi secara aktif dalam pelajaran matematika online serta siswa yang tidak mampu memahami materi yang disampaikan oleh guru. Tingkatan kecemasan mengajar matematika memberikan dampak berbeda terhadap metode yang dipakai guru pada pembelajaran online. Responden dengan tingkat kecemasan mengajar tinggi secara umum menggunakan media whatsapp. Responden dengan tingkat kecemasan mengajar matematika sedang menggunakan media pembelajaran seperti video dari youtube. Responden dengan tingkat kecemasan mengajar matematika rendah menggunakan metode pemecahan masalah, metode kooperatif serta diskusi tanya jawab melalui google meet maupun google classroom.
\end{abstract}

Kata kunci: Kecemasan mengajar matematika; metode pengajaran guru; pembelajaran online.

\begin{abstract}
The aims of this research were to describe the anxiety level of mathematics teachers in schools regarding learning online, the factors of anxiety teaching mathematics in learning online, the impacts of mathematics teaching anxiety on teacher teaching methods in learning online. The research method used is descriptive qualitative research methods. The study was conducted on 31 mathematics teachers who teachlearning online. Data were collected through a Mathematics Teaching Anxiety Scale 19 items (MTAS) questionnaire. The data analysis technique used consists of three stages, namely data reduction, data display and data verification. The results showed thatmathematics teaching anxiety level oflearning online there were 7 people (22.6\%) in the, 14 (58\%) in the medium anxiety level category and 6 people (19.4\%) in the anxiety level category. low. The anxiety of teaching mathematics that most teachers feel is related to students who cannot participate actively in online mathematics lessons and students who are unable to understand the material presented by the teacher. The level of anxiety in teaching mathematics has a different impact on the methods used by teachers in online learning. Respondents with a high level of teaching anxiety generally use media WhatsApp. Respondents with anxiety levels teaching mathematics are using learning media such as videos from YouTube. Respondents with a low level of anxiety teaching mathematics used problem solving methods, cooperative methods and question and answer discussions through google meet and google classroom.
\end{abstract}

Keywords: Anxiety teaching mathematics; online learning; teacher teaching methods .

This is an open access article under the Creative Commons Attribution 4.0 International License 
DOI: https://doi.org/10.24127/ajpm.v10i3.3745

\section{PENDAHULUAN}

Pembelajaran online merupakan strategi yang niscaya dalam situasi pandemi. Akan tetapi masih banyak ditemui kendala selama pembelajaran online, salah satunya adalah timbulnya kecemasan guru dalam mengajar. Secara khusus, kecemasan matematika bagi calon guru terbagi menjadi dua domain yaitu kecemasan umum dan kecemasan mengajar matematika. Kecemasan umum berkaitan dengan pengetahuan matematis dan kepercayaan diri akan matematika, sedangkan kecemasan mengajar matematika berkaitan dengan kecemasan individu terkait dengan kemampuan mengajar matematikanya (Dzulfikar, 2016).

Matematika yang abstrak, menjadi salah satu mata pelajaran yang sulit diajarkan melalui pembelajaran tanpa tatap muka atau pembelajaran online. Pembelajaran online menuntut para guru untuk mahir menggunakan tekhnologi dalam menyampaikan materi matematika. Para gurupun harus membuat bahan ajar, membuat soal-soal ujian, menyusun rencana pembelajaran serta merancang penilaian pembelajaran berbasis tekhnologi. Tidak sedikit para guru mengalami kendala tekhnis seperti jaringan internet. Hal ini menimbulkan kecemasan para guru matematika dalam pembelajaran online.

Berdasarkan hasil penelitian, ditemukan hubungan tingkat rendah antara kecemasan mengajar matematika guru dan persepsi mereka terhadap penggunaan tekhnologi dalam pengajaran matematika (Tatar et al., 2015). Sedangkan kecemasan mengajar matematika dapat muncul jika pembelajaran tidak dapat dilakukan sesuai dengan skenario yang dirancang serta adanya rasa cemas jika harapan dari tujuan proses pembelajaran tidak tercapai (Heru et al., 2020)
Pembelajaran yang seharusnya dilalui dengan menyenangkan berubah menjadi hal yang menakutkan dan telah menimbulkan kecemasan para guru dalam mengajar matematika. Penggunaan teknologi dalam pembelajaran online menjadi tantangan tersendiri bagi para guru dalam menyampaikan materimateri matematika. Guru harus mampu mempersiapkan pembelajaran berbasis online dengan baik agar pembelajaran tetap berjalan sesuai dengan tujuan pendidikan. Ketika guru mampu mengatasi kecemasan dalam mengajar matematika secara online, maka siswapun akan menyerap materi dengan baik dan bermakna.

Sejauh ini studi tentang kecemasan matematika cenderung membahas tentang kecemasan matematika pada siswa (Quander \& Stuart, 2016; Vukovic et al., 2013; Istikomah \& Wahyuni, 2018) atau pada calon guru matematika (Goetz et al., 2013; Gresham \& Burleigh, 2019; Heru et al., 2020) mengabaikan kecemasan proses pengajaran matematika pada guru. Banyak penelitian (Alkan et al., 2019); Peker \& Ertekin, 2011; Vukovic et al., 2013) menunjukkan bahwa beberapa siswa di berbagai kelas sekolah memiliki sikap negatif terhadap matematika yang pada akhirnya menimbulkan perasaan cemas dalam matematika, dan kecemasan siswa dalam matematika disebabkan oleh alasan seperti kepribadian, orang tua, teman sebaya serta guru bersama dengan strategi dan gaya mengajar mereka (Alkan et al., 2019).

Hubungan pembelajaran online dengan kecemasan mengajar matematika dipilih sebagai objek penelitian atas tiga alasan. Alasan pertama, pembelajaran online telah mendapatkan respons yang luas atas kesulitankesulitan yang dialami baik oleh siswa 
maupun guru. Hubungan antara siswaguru pun berubah sejalan dengan diberlakukakannya pembelajaran online. Kedua, belum banyak perhatian diberikan pada analisis hubungan pembelajaran online dengan kecemasan mengajar matematika dan dampaknya pada metode pengajaran guru. Ketiga, analisis kecemasan mengajar matematika dalam pembelajaran online sangat diperlukan mengingat potensi yang besar proses pembelajaran online dalam meningkatkan kecemasan mengajar matematika. Ketiga alasan tersebut memperlihatkan bahwa kecemasan mengajar matematika merupakan suatu persoalan yang krusial dan mendesak untuk dipahami sebagai landasan kebijakan sistem pendidikan.

Penelitian ini sangat perlu dilakukan untuk dapat meningkatkan keberhasilan dalam proses belajar mengajar matematika, khususnya ditengah pemberlakuan pembelajaran daring. Sejalan dengan itu, penelitian ini akan mendeskripsikan 1) tingkat kecemasan guru matematika di sekolah terhadap pembelajaran online; 2) faktorfaktor kecemasan mengajar matematika pada pembelajaran online, 3) dampak dari kecemasan mengajar matematika terhadap metode mengajar guru pada pembelajaran online. Ketiga jawaban dari penelitian ini diharapkan akan memberi pemahaman tentang kecemasan guru dalam mengajar pada pembelajaran online serta dampaknya pada metode mengajar guru sehingga dapat menjadi pertimbangan dalam mengatasi kecemasan mengajar guru.

\section{METODE PENELITIAN}

Hubungan antara pembelajaran online dengan kecemasan mengajar matematika dijelaskan melalui penelitian kualitatif yang bersandar pada data primer dan data sekunder.
Tingkat kecemasan mengajar matematika dikumpulkan melalui kuesioner Mathematics Teaching Anxiety Scale (MTAS) merujuk pada (Alkan et al., 2019) yang sudah dimodifikasi dan divalidasi oleh pakar. Kuesioner sebanyak 19 item mengguna-kan skala Likert dengan pilihan jawaban sangat setuju, setuju, tidak memiliki pendapat, tidak setuju, dan sangat tidak setuju. Instrument data kualitatif terdiri dari data primer yaitu tingkat kecemasan mengajar matematika pada guru, faktorfaktor kecemasan mengajar matematika serta metode yang dipakai oleh guru pada pembelajaran online berdasarkan tingkatan kecemasan mengajar matematika. Data sekunder terdiri dari latar belakang dan gender guru. Baik data primer maupun sekunder digunakan sebagai dasar analisis hubungan antara pembelajaran online dengan kecemasan mengajar matematika.

Penelitian ini melibatkan kelompok guru yang mengajar matematika pada pembelajaran online sebanyak 31 orang. Kelompok guru dipilih berdasarkan pengalaman mengajar matematika pada pembelajaran online yang akan dianalisis bagaimana tingkat kecemasan mengajar matematika, faktor-faktor kecemasan mengajar matematika serta implikasinya pada metode mengajar yang dilakukan oleh guru. Data dikumpulkan dengan memberikan kuesioner Mathematics Teaching Anxiety Scale (MTAS) sebanyak 19 item kepada partisipan.

Penelitian ini berlangsung melalui tahapan pengumpulan data serta wawancara guru matematika. Data mengenai tingkat kecemasan mengajar matematika dikumpulkan melalui kuesioner kemudian diklasifikasikan berdasarkan tingkatan tinggi, sedang dan rendah. 
DOI: $\underline{\text { https://doi.org/10.24127/ajpm.v10i3.3745 }}$

Faktor-faktor kecemasan mengajar matematika serta metode yang dipakai oleh guru pada pembelajaran online dikumpulkan melalui wawancara kepada guru berdasarkan tingkat kecemasan mengajar matematika. Datadata yang telah dikumpulkan menjadi landasan bagi analisis hubungan pembelajaran online dengan kecemasan mengajar matematika.

Proses analisis data dilakukan dengan tiga tahap analisis. Tiga tahap analisis yaitu: (a) reduksi data sebagai proses penataan data dalam bentuk yang lebih sistematis, khususnya secara tematis; (b) display data sebagai usaha menghadirkan hasil penelitian dalam bentuk tabel dan grafik (dalam bentuk kutipan-kutipan wawancara); dan (c) verifikasi data sebagai suatu tahapan penyimpulan data, khususnya mengikuti tren dari data yang diperoleh. Tahapan analisis yang digunakan memungkinkan dirumuskan kesimpulan-kesimpulan atas hubungan pembelajaran online dengan kecemasan mengajar matematika pada masa pandemi COVID-19.

\section{HASIL DAN PEMBAHASAN Hasil}

Pembelajaran online telah membawa berbagai akibat dalam proses pembelajaran di kelas khususnya pada kecemasan mengajar matematika pada guru. Bukti bahwa munculnya kecemasan mengajar matematika yang disebabkan oleh pembelajaran online dapat dibuktikan dengan 3 fakta yaitu tingkat kecemasan mengajar matematika, faktor-faktor yang menyebabkan kecemasan mengajar matematika pada pembelajaran online serta metode mengajar yang dilakukan guru pada pembelajaran online. Ketiga fakta/bukti tersebut dibicarakan secara seksama pada bagian-bagian berikut ini.

\section{Tingkat Kecemasan Mengajar Matematika}

Sebanyak 31 guru matematika terdiri dari 10 guru laki-laki dan 21 guru perempuan yang mengajar pada pembelajaran online selama masa pandemi telah mengisi kuesioner Mathematics Teaching Anxiety Scale (MTAS). Kuesioner sebanyak 19 item menggunakan skala likert dengan jawaban sangat setuju, setuju, tidak memiliki pendapat, tidak setuju, sangat tidak setuju. Skor rata-rata adalah 60,58 dengan standar deviasi 12,3. Persentase tingkat kecemasan mengajar matematika disajikan pada Tabel 1 .

Dari Tabel 1, terlihat bahwa tingkat kecemasan mengajar matematika pada pembelajaran online paling banyak berada pada tingkatan sedang dengan persentase sebesar 58\% atau sebanyak 18 orang.

Tabel 1. Persentase tingkat kecemasan mengajar matematika

\begin{tabular}{cccccc}
\hline Kriteria & Interval & Laki-laki & Perempuan & Jumlah & Persentase \\
\hline Tinggi & $\geq 72,88$ & 3 & 4 & 7 & $22,6 \%$ \\
Sedang & $48,28 \leq x<72,88$ & 4 & 14 & 18 & $58 \%$ \\
Rendah & $>48,28$ & 3 & 3 & 6 & $19,4 \%$ \\
\hline & Total & 10 & 21 & 31 & $100 \%$ \\
\hline
\end{tabular}

Faktor-Faktor Penyebab Kecemasan Mengajar Matematika Pada Pembelajaran Online

Setelah mengisi kuesioner Mathematics Teaching Anxiety Scale
(MTAS), guru dengan tingkat kecemasan mengajar matematika tinggi, sedang dan rendah diwawancarai mengenai faktor-faktor penyebab kecemasan mengajar matematika. Hasil 
wawancara kepada dua orang responden dengan tingkat kecemasan mengajar matematika tinggi adalah faktor-faktor yang menyebabkan munculnya kecemasan mengajar matematika yaitu kemampuan daya tangkap setiap siswa berbeda, tidak tersedianya handphone untuk setiap siswa, pembelajaran menjadi tidak menarik, tidak bisa menerapkan pembelajaran aktif dan kreatif, tidak bisa menerapkan pembelajaran berbasis penyelesaian masalah. Selain itu guru mengalamai kecemasan mengajar matematika dalam pembelajaran online ketika menjelaskan konsep rumus matematika khususnya jika pembelaja-ran hanya menggunakan grup Whatsapp.

Hasil wawancara pada responden dengan tingkat kecemasan mengajar matematika sedang adalah salah satu faktor yang menyebabkan munculnya perasaan cemas ketika mengajar matematika pada pembelajaran online yaitu minat anak yang menurun pada pembelajaran online karena materi yang disampaikan tidak diterima dengan baik oleh setiap anak. Selain itu, perasaan cemas juga muncul jika siswa terkendala jaringan internet.

Hasil wawancara kepada responden dengan tingkat kecemasan mengajar matematika rendah adalah ketidakhadiran siswa pada pembelajaran online, Pencapaian pemahaman siswa terhadap konsep yang disampaikan dalam pembelajaran online. Serta kurangnya motivasi orang tua dalam membimbing anaknya untuk belajar.

Berdasarkan data di atas, faktorfaktor penyebab kecemasan mengajar matematika pada pembelajaran online dirangkum pada Tabel 3.

Tabel 3 Faktor-faktor kecemasan mengajar guru pada pembelajaran online

\begin{tabular}{cl} 
No & \multicolumn{1}{c}{ Faktor } \\
1 & Perbedaan kemampuan daya tangkap siswa terhadap materi matematika \\
2 & Tidak semua siswa memiliki handphone/laptop untuk pembelajaran \\
3 & Pembelajaran berkesan tidak menarik \\
4 & Tidak bisa menerapkan pembelajaran aktif dan kreatif dan berbasis penyelesaian \\
& masalah \\
5 & Minat dan motivasi belajar siswa yang menurun karena belajar online \\
6 & Materi yang disampaikan tidak diterima dengan baik oleh setiap anak. \\
7 & Terjadi kendala teknis seperti jaringan \\
\hline
\end{tabular}

\section{Metode Mengajar yang dilakukan Guru pada Pembelajaran Online}

Munculnya kecemasan mengajar matematika berimplikasi pada metode mengajar yang dilakukan oleh guru. Peneliti mewawancarai responden terkait metode mengajar yang dipakai selama pembelajaran online. Pada responden dengan tingkat kecemasan matematika tinggi, metode yang dipakai pada pembelajaran online adalah banyak mengunduh materi dari youtube yang dihubungkan dengan buku paket untuk mengerjakan soal kemudian memberikan kesempatan kepada siswa untuk menanyakan kepada guru ketika ada kesulitan. Selain itu, responden juga mengirimkan video dan meminta siswa memahami pelan-pelan tanpa paksaan terhadap materi yang sedang dibahas.

Pada responden dengan tingkat kecemasan matematika sedang, metode yang dipakai pada pembelajaran online adalah metode tanya jawab, video pembelajaran, membuat bahan presentasi menggunakan akun canva, memper- 
siapkan rencana pembelajaran sebelum mengajar, memberikan materi dalam bentuk pdf atau video satu hari sebelum pembelajaran, memberikan quiz dalam bentuk microsoft teams untuk menguji pemahaman siswa, mengulas atau membahas quiz di awal pertemuan sebelum memasuki topik baru.

Pada responden dengan tingkat kecemasan matematika rendah, metode yang dipakai pada pembelajaran online adalah mempersiapkan bahan dari jauhjauh hari, mengajar dengan menggunakan metode saintifik, problem solving, ceramah, tanya jawab, penugasan media whatsapp, youtube dan google form, serta memberikan kesempatan seluasnya untuk siswa dalam pengumpulan tugas-tugas, menggunakan berbagai media seperti gambar, PPT, video, alat peraga dan lain-lain.

Berdasarkan data di atas, metode mengajar guru pada pembelajaran online dirangkum pada Tabel 4.

Tabel 4 Metode mengajar guru pada pembelajaran online

\begin{tabular}{|c|c|}
\hline No & Metode \\
\hline 1 & $\begin{array}{l}\text { Metode tanya jawab melalui } \\
\text { whatsapp grup }\end{array}$ \\
\hline 2 & $\begin{array}{l}\text { Memberikan modul dan bank soal } \\
\text { secara online }\end{array}$ \\
\hline 3 & $\begin{array}{l}\text { Mengajar dengan menggunakan } \\
\text { media video pembelajaran dan } \\
\text { PPT }\end{array}$ \\
\hline 4 & $\begin{array}{l}\text { Memberikan evaluasi melalui quiz } \\
\text { atau google formulir }\end{array}$ \\
\hline 5 & $\begin{array}{l}\text { Pembelajaran menggunakan zoom } \\
\text { meeting atau google meet }\end{array}$ \\
\hline
\end{tabular}

\section{Pembahasan}

Pada Tabel 2, tingkat kecemasan mengajar matematika pada pembelajaran online dalam penelitian ini ditemukan sebanyak 7 orang $(22,6 \%)$ kategori tingkat kecemasan tinggi, sebanyak 14 orang (58\%) kategori tingkat kecemasan sedang dan sebanyak 6 orang $(19,4 \%)$ kategori tingkat kecemasan rendah. Secara umum, tingkat kecemasan mengajar matematika guru pada pembelajaran online berada pada tingkatan sedang. Kecemasan mengajar tingkat sedang yaitu guru sudah menggunakan berbagai media untuk melaksanakan pembelajaran online, namun masih muncul kecemasan guru terhadap ketidakmampuan siswa dalam memahami materi matematika yang disampaikan pada pembelajaran online. Menurut (Alkan et al., 2019) kecemasan mengajar matematika muncul ketika guru merasa dibawah tekanan untuk mengajar dan frustrasi dengan kurangnya kemajuan siswa dalam matematika.

Seseorang pada kategori sedang dapat berpindah pada kategori rendah atau tinggi (Yuliani et al., 2019). Tingkat kecemasan mengajar matematika dapat menurun atau meningkat seiring dengan pengetahuan mengenai penggunaan tekhnologi dan tingkat literasi komputer dalam pengajaran matematika (Tatar et al., 2015). Oleh karena itu, pada pembelajaran online yang menuntut penggunaan tekhnologi mengharuskan guru untuk menguasai tekhnologi supaya dapat menurunkan kecemasan mengajar matematika.

Temuan mengenai kecemasan mengajar matematika pada penelitian ini bahwa skor tertinggi pada jawaban kuesioner adalah terkait kecemasan responden terhadap tingkat pemahaman siswa pada materi yang disampaikan. Ini terjadi dikarenakan banyak ditemuinya kendala-kendala seperti jaringan internet yang dapat menghambat berjalannya pelaksanaan pembelajaran secara online. Kecemasan mengenai tingkat pemahaman siswa akan materi yang diajarkan, menimbul- 
kan kecemasan guru terkait metode pembelajaran seperti apa yang tepat untuk digunakan pada pembelajaran online. Kurangnya penge-tahuan guru mengenai pembelajaran online pun menjadi faktor munculnya kecemasan mengajar matematika.

Faktor-faktor penyebab munculnya kecemasan mengajar matematika yang ditemui pada penelitian ini adalah tidak puasnya guru dalam menyampaikan materi secara online. Responden dengan tingkat kecemasan tinggi merasa dengan pembelajaran online yang serba terbatas membuat guru tidak bisa kreatif dan tidak bisa menyampaikan pembelajaran berbasis masalah. Responden dengan tingkat kecemasan mengajar matematika sedang dan rendah merasa cemas jika siswa kurang berminat dalam mengikuti pembelajaran matematika secara online. Akibatnya siswapun tidak bersemangat dalam mempelajari bahan-bahan pembelajaran yang diberikan oleh guru. Selain itu, siswapun tidak bersemangat untuk membuka website atau akun yang digunakan untuk pembelajaran online. Keterlibatan orangtua dalam pembelajaran online juga menjadi faktor munculnya kecemasan mengajar matematika. Disatu sisi banyak orangtua yang kurang mengawasi anakanak pada pelaksanaan pembelajaran online disisi lain banyak orangtua yang mengerjakan sendiri tugas-tugas anaknya sehingga hasil belajar siswa menjadi tidak natural.

Kecemasan mengajar matematika mempengaruhi metode mengajar guru. Responden dengan tingkat kecemasan mengajar tinggi secara umum menggunakan media whatsapp, mengajar dengan mengirimkan video pembelajaran yang diunduh dari youtube kemudian menjelaskan materi berdasarkan video dan buku paket.
Selanjutnya responden mempersilahkan siswa untuk mema-hami materi sendiri secara pelan-pelan. Dalam hal ini, kecemasan mengajar matematika dirasakan pada saat para siswa tidak mampu berpartisipasi aktif pada pembelajaran online.

Responden dengan tingkat kecemasan mengajar matematika sedang menggunakan media pembelajaran seperti video dari youtube, membuat kuis sebelum dan sesudah pembelajaran serta menyiapkan rencana pembelajaran sebelum jadwal pembelajaran berlangsung. Pada kategori ini, responden merasakan kecemasan pada saat siswa tidak mampu memahami operasi matematika terkait materi yang disampaikan. Oleh karena itu dalam mengatasi kecemasan-nya terlihat responden berusaha mempersiapkan pelaksanaan pembelajaran secara maksimal dengan membuat perencanaan pembelajaran serta instrumen evaluasi dari berbagai media.

Responden dengan tingkat kecemasan mengajar matematika rendah mempersiapkan rencana pembelajaran dari jauh-jauh hari sebelum pembelajaran berlangsung. Mereka menggunakan berbagai media sosial untuk memfasilitasi pembelajaran. Responden menggunakan metode pemecahan masalah, metode kooperatif serta diskusi tanya jawab melalui google meet maupun google classroom. Hal ini sejalan dengan penelitian bahwa gaya mengajar berbasis masalah terbukti memiliki dampak menguntungkan yang substansial pada kecemasan matematika (Van der Sandt \& O'Brien, 2017). Responden pada katergori ini merasa yakin bahwa mereka memiliki cukup pengetahuan tentang pembelajaran online. Rasa percaya diri yang tinggi dan kemampuan serta pengetahuan matematika yang baik merupakan 
syarat dasar bagi guru dalam mengajarkan matematika (Wilson, 2009).

Dari uraian di atas, faktor-faktor yang menyebabkan kecemasan mengajar matematika secara garis besar adalah penggunaan tekhnologi. hal ini sejalan dengan penelitian bahwa masih banyak guru yang kurang pemahaman dalam IPTEK apalagi guru lama, atau guru tradisional sehingga pembelajaran daring menjadi tidak menarik. Masih kurangnya sarana dan prasarana yang mendukung seperti android dan kuota (Anggianita et al., 2020). Kualitas guru berkaitan dengan kemampuan guru menggunakan teknologi informasi dalam proses pembelajaran yang dinilai masih sangat rendah, dipengaruhi oleh faktor usia dan kepemilikan laptop (Anggianita et al., 2020).

Kecemasan yang dimiliki oleh guru bisa menimbulkan stress psikologis seperti burnout (Maslach dan Leiter, 2016). Burnout yang dimaksud adalah penurunan kualitas pengajaran dan berkurangnya kemampuan untuk menyampaikan materi ketika mengajar (Lancu et al., 2017).

\section{KESIMPULAN DAN SARAN}

Berdasarkan hasil penelitian dan pembahasan dapat disimpulkan bahwa level kecemasan mengajar matematika guru pada pembelajaran online secara umum berada pada tingkatan sedang. Kecemasan mengajar matematika guru yang paling banyak dirasakan adalah terkait siswa yang tidak dapat berpartisipasi secara aktif dalam pelajaran matematika online serta siswa yang tidak mampu memahami materi yang disampaikan oleh guru. Hal ini dikarenakan adanya banyak kendala seperti jaringan internet, tidak tersedianya sarana yang dimiliki oleh siswa sehingga dapat menghambat pelaksanaan pembelajaran online.
Tingkatan kecemasan mengajar matematika memberikan dampak berbeda terhadap metode yang dipakai guru pada pembelajaran online. Kurangnya pengetahuan guru mengenai pembelajaran online pun menjadi faktor munculnya kecemasan mengajar matematika.

Dengan mengambil perspektif pembelajaran online pada kecemasan mengajar matematika yang dialami oleh guru, telah memungkinkan terlihat kendala dalam pembelajaran matematika yang terjadi selama pandemi. Kecemasan pada pembelajaran online tidak hanya dialami oleh siswa, namun juga dialami oleh guru yang jika diabaikan bisa memberikan efek yang tidak baik bagi pemahaman siswa terhadap materi matematika.

Kecemasan mengajar guru matematika berdampak pada metode pengajaran yang dilakukan oleh guru. Responden dengan tingkat kecemasan mengajar tinggi secara umum menggunakan media whatsapp, mengajar dengan mengirimkan video pembelajaran yang diunduh dari youtube kemudian menjelaskan materi berdasarkan video dan buku paket. Responden dengan tingkat kecemasan mengajar matematika sedang menggunakan media pembelajaran seperti video dari youtube, membuat kuis sebelum dan sesudah pembelajaran serta menyiapkan rencana pembelajaran sebelum jadwal pembelajaran berlangsung. Responden dengan tingkat kecemasan mengajar matematika rendah menggunakan metode pemecahan masalah, metode kooperatif serta diskusi tanya jawab melalui google meet maupun google classroom.

Studi ini terbatas pada pemetaan kecemasan mengajar matematika sebagaimana direpresentasikan pada wawancara sehingga data yang diguna- 
kan memiliki keterbatasan perspektif. Hal ini dilakukan sejalan dengan adanya social distancing yang menghambat proses penelitian lapangan. Untuk pemahaman yang lebih mendalam perlu dilakukan observasi langsung untuk melihat proses pembelajaran online. Sejalan dengan itu dibutuhkan penelitian lanjutan yang mengakomodasi penelitian empiris yang berbasis pada observasi dan wawancara pada berbagai pihak dan sekolah selain untuk pemahaman yang komprehensif untuk untuk memungkinkan dikembangkannya kebijakan yang tepat sasaran.

\section{DAFTAR PUSTAKA}

Alkan, V., Coşguner, T., \& Fidan, Y. (2019). Mathematics Teaching Anxiety Scale: Construction, Reliability and Validity. International Journal of Assessment Tools in Education, October, 506-520. https://doi.org/10.21449/ijate.625 423

Anggianita, S., Yusnira, Y., \& Rizal, M. S. (2020). Persepsi Guru terhadap Pembelajaran Daring di Sekolah Dasar Negeri 013 Kumantan. Journal of Education Research, 1(2), 177-182. https://doi.org/10.37985/joe.v1i2. 18

Arikunto, S. (2013). Prosedur Penelitian Suatu Pendekatan Praktik. Jakarta: Rineka Cipta. Azwar. Rineka Cipta.

Dzulfikar, A. (2016). Kecemasan Matematika Pada Mahasiswa Calon Guru Matematika. JMPM: Jurnal Matematika Dan Pendidikan Matematika, 1(1), 34. https://doi.org/10.26594/jmpm.v1i 1.508

Goetz, T., Bieg, M., Lüdtke, O., Pekrun,
R., \& Hall, N. C. (2013). Do Girls Really Experience More Anxiety in Mathematics? Psychological Science, 24(10), 2079-2087. https://doi.org/10.1177/09567976 13486989

Gresham, G., \& Burleigh, C. (2019). Exploring early childhood preservice teachers' mathematics anxiety and mathematics efficacy beliefs. Teaching Education, 30(2), 217-241. https://doi.org/10.1080/10476210. 2018.1466875

Heru, H., Yuliani, R. E., \& Nery, R. S. (2020). Kecemasan mengajar matematika mahasiswa calon guru dalam melakukan praktik mengajar. Jurnal Math Educator Nusantara: Wahana Publikasi Karya Tulis Ilmiah Di Bidang Pendidikan Matematika, 6(1), 112.

https://doi.org/10.29407/jmen.v6i 1.14308

Istikomah, E., \& Wahyuni, A. (2018). Student's Mathematics Anxiety on The Use of Technology in Mathematics Learning. JRAMathEdu (Journal of Research and Advances in Mathematics Education), 3(2), 69. https://doi.org/10.23917/jramathe du.v3i2.6364

Lancu, A. E., Rusu, A., Maroiu, C., Pacurar, R., Laurentiu, L. (2017). The Effectiveness of Interventions Aimed at Reducing Teacher

Burnout: a Meta-Analysis. Educational Psychology Review. 30(2), 373396.

Maslach, C., Leiter, M. (2016). Understanding The Burnout Experience: Recent 
DOI: https://doi.org/10.24127/ajpm.v10i3.3745

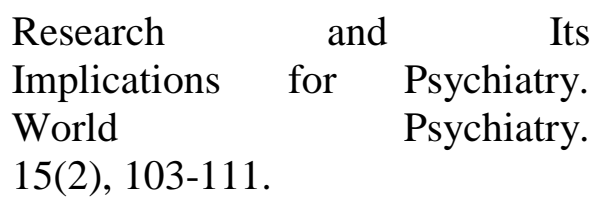

Peker, M., \& Ertekin, E. (2011). The relationship between mathematics teaching anxiety and mathematics anxiety. New Educational Review, 23(1), 213-226.

Quander, J., \& Stuart, V. (2016). Math Anxiety in Elementary School. National Coucil of Teachers of Mathematics, 19(7), 405-407.

Rayner, V., Pitsolantis, N., \& Osana, H. (2009). Mathematics anxiety in preservice teachers: Its relationship to their conceptual and procedural knowledge of fractions. Mathematics Education Research Journal, 21(3), 60-85. https://doi.org/10.1007/BF032175 53

Tatar, E., Zengin, Y., \& Kağizmanli, T. B. (2015). What is the relationship between technology and mathematics teaching anxiety? Educational Technology and Society, 18(1), 67-76.

Van der Sandt, S., \& O'Brien, S. (2017). Impact of Instructor Teaching Style and Content Course on Mathematics Anxiety of Preservice Teachers Suriza Van der Sandt \& Steve O 'Brien. Journal of Technology Education, 29(1), 95-111.

Vukovic, R. K., Kieffer, M. J., Bailey, S. P., \& Harari, R. R. (2013). Mathematics anxiety in young children: Concurrent and longitudinal associations with mathematical performance. Contemporary Educational Psychology, 38(1), 1-10. https://doi.org/10.1016/j.cedpsych .2012.09.001
Wilson, S. (2009). “ Better You Than Me ": Mathematics Anxiety and Bibliotherapy in Primary Teacher Professional Learning . Crossing Divides: Proceedings of the 32nd Annual Conference of the Mathematics Education Research Group of Australasia (Vol. 2)., 2, 603-610.

Yuliani, R. E., Suryadi, D., \& Dahlan, J. A. (2019). Analysis of mathematics anxiety of junior high school students. Journal of Physics: Conference Series, 1157(4). https://doi.org/10.1088/17426596/1157/4/042053 